\title{
Aspectos clínicos e patológicos da intoxicação por Sida carpinifolia (Malvaceae) em caprinos no Rio Grande do Sul ${ }^{1}$
}

\author{
Edson M. Colodel ${ }^{2 *}$, David Driemeier ${ }^{3}$, Alexandre P. Loretti ${ }^{3}$, Eduardo J. Gimeno ${ }^{4}$, \\ Sandra D. Traverso ${ }^{5}$, Anderson L. Seitz ${ }^{5}$ e Priscila Zlotowski ${ }^{6}$
}

\begin{abstract}
Colodel E.M., Driemeier D., Loretti A.P., Gimeno E.J., Traverso S.D., Seitz A.L. \& Zlotowski P. 2002. [Clinical and pathological aspects of Sida carpinifolia poisoning in goats in Rio Grande do Sul.] Aspectos clínicos e patológicos da intoxicação por Sida carpinifolia (Malvaceae) em caprinos no Rio Grande do Sul. Pesquisa Veterinária Brasileira 22(2):51-57. Setor de Patologia Veterinária, Depto Patologia Clínica Veterinária, Faculdade de Veterinária, Universidade Federal do Rio Grande do Sul, Av. Bento Gonçalves 9090, Cx. Postal 15094, Porto Alegre, RS 91540-000, Brazil.

This report includes the clinical and pathological studies of a lysosomal storage disease which spontaneously occurred in three flocs of goats e after consumption of Sida carpinifolia, the predominant plant in the paddocks where the animals were grazing. In the outbreaks a total of 25 out of 51 animals were affected. Post-mortem examination was performed on 11 goats. The disease was experimentally induced by dosing goats with Sida carpinifolia. The plant was administered in natura or dried to 3 animals. No clinical or pathological changes were observed in one goat dosed with Sida rhombifolia ad libidum during 40 days. Clinical signs of the poisoning were ataxia, hypermetria, muscle tremors in the head and neck and disorders of deglutition. The clinical signs were exacerbated by movement. After the surviving animals had been moved to other pastures and stopped eating the plant, clinical signs were still observed during 24 months. At necropsy, no significant gross lesions were observed. Microscopic lesions included various degrees of vacuolization in the cytoplasm of neurons and glial cells. Similar lesions were observed in the acinar pancreatic cells, hepatocytes, proximal convoluted tubular cells, follicular epithelial cells of the thyroid gland and macrophages of lymph nodes. In the surviving animals, mild neuronal cytoplasmic vacuolization was observed, and few cells were eosinophilic and shrunken. In these cases neurons, especially Purkinje cells, had disappeared. Through the histochemical study of the cerebellar sections, the lysosomal storage disease was characterized as an alpha-mannosidosis. The vacuoles within the Purkinje cells strongly reacted with lectins of Concanavalia ensiformis, Triticum vulgaris and succinylated Triticum vulgaris. The pattern observed in this investigation is similar to those seen in other poisonings by swainsonine-containing plants.
\end{abstract}

INDEX TERMS: Sida carpinifolia, Malvaceae, lysosomal storage disease, $\alpha$-mannosidosis, goats, lectins.

\footnotetext{
${ }^{1}$ Aceito para publicação em 2 de abril de 2002.

Trabalho realizado com suporte financeiro do CNPq (Proc. 476443/01-6).

${ }^{2}$ Depto Clínica Médica Veterinária, Universidade Federal de Mato Grosso (UFMT),

Cuiabá, MT. Autor para correspondência. E-mail: moleta@terra.com.br

${ }^{3}$ Departamento de Patologia Clínica Veterinária, UFRGS, Cx. Postal 15094, Porto Alegre, RS 91540-000.

${ }^{4}$ Instituto de Patologia, Faculdade de Ciências Veterinárias, Universidade Nacional de La Plata, La Plata, Argentina.

${ }^{5}$ Curso de Pós-Graduação em Ciências Veterinárias, Área de Patologia, CPGVEt-UFRGS.

${ }^{6}$ Estagiária do Departamento de Patologia Clínica Veterinária; Bolsista de Iniciação Científica, Fundação de Amparo à Pesquisa do Rio Grande do Sul (FAPERGS).
}

RESUMO.- Este trabalho inclui os estudos clínicos e patológicos da doença de armazenamento lisossomal induzida pelo consumo espontâneo de Sida carpinifolia. A enfermidade foi observada em três rebanhos, que juntos eram compostos por 51 caprinos, dos quais, 25 foram afetados e 11 necropsiados. Nos três surtos, $S$. carpinifolia era a vegetação predominante nos piquetes ocupados pelos animais. Clinicamente, a doença caracterizou-se por distúrbios neurológicos que consistiam de ataxia, hipermetria, posturas anormais, tremores musculares afetando principalmente as regiões da cabeça e pescoço, dificuldade para ingestão de alimentos e quedas frequientes. Estes sinais clínicos eram exacerbados pela movi- 
mentação. Em alguns animais, embora com um quadro clínico estabilizado, as alterações neurológicas persistiram durante 24 meses após sua retirada dos piquetes infestados por S. carpinifolia. A doença foi reproduzida administrando-se S. carpinifolia, in natura ou seca à sombra, para 3 caprinos. Um caprino recebeu Sida rhombifolia, ad libidum, por 40 dias e não desenvolveu alterações clínicas ou patológicas. Na necropsia não havia alterações. Microscopicamente, as principais alterações foram distensão e vacuolização citoplasmáticas em neurônios e, em menor intensidade, em células da glia do sistema nervoso central. Alterações similares foram observadas em células acinares pancreáticas, hepatócitos, células tubulares renais, células foliculares epiteliais da tireóide e macrófagos de órgãos linfóides. Nos animais que não mais ingeriam S. carpinifolia por períodos de um mês ou mais, observou-se uma diminuição da vacuolização citoplasmática de neurônios, que apresentavam citoplasma eosinofílico e aspecto enrugado. Nestes casos, notou-se também desaparecimento neuronal especialmente em células de Purkinje e gliose local. Em cortes cerebelares, esta doença de armazenamento foi caracterizada como ?-manosidose pelo estudo histoquímico por lectinas. Os vacúolos nas células de Purkinje reagiram fortemente com as lectinas Concanavalia ensiformis, Triticum vulgaris e Triticum vulgaris succinilado. $\mathrm{O}$ padrão obtido neste estudo é similar ao encontrado em intoxicação por plantas que apresentam swainsoniana como princípio tóxico.

TERMOS DE INDEXAÇÃO: Sida carpinifolia, Malvaceae, doença de armazenamento lisossomal, a-manosidose, caprinos, lectinas.

\section{INTRODUÇÃO}

Sida carpinifolia L.f. (guanxuma, chá-da-índia), da família Malvaceae, tem distribuição pantropical e é freqüente em locais úmidos e sombreados das Regiões Sul, Sudeste e Centro-Oeste do Brasil. É uma planta subarbustiva, perene, ereta, com 0,3 a $0,7 \mathrm{~m}$ de altura (Fig. 1) que se propaga por sementes (Lorenzi 2000).

S. carpinifolia foi primeiramente associada com doença de armazenamento lisossomal em caprinos por Driemeier et al. (2000). Posteriormente, doença similar foi diagnosticada em pôneis (Loretti et al. 2002). Recentemente, constatou-se que bovinos e ovinos podem ser naturalmente afetados (Driemeier, dados não publicados). Da planta isolou-se o alcalóide indolizidina 1,2,8-triol, denominado swainsonina (Colodel et al. 2002) que inibe as enzimas a-manosidase e a-manosidase II do aparelho de Golgi. Segue-se alteração no processamento de glicoproteínas e conseqüente acúmulo de oligossacarídeos (Stegelmeier et al. 1995, Balogh et al. 1999), prejudicando a função e causando a morte da célula (Agamanolis 1995). Plantas tóxicas com mesmo princípio ativo são descritas como causa de consideráveis perdas econômicas, principalmente no Oeste dos Estados Unidos [Astragalus spp e Oxytropis spp] (Kingsbury 1964, James \& Nielsen 1990), na Austrália [Swainsona spp] (Colegate et al. 1979) e em Moçambique [Ipomoea carnea] (Balogh et al. 1999). No Brasil, quadros clínicos semelhantes são associados ao consumo de Ipomoea fistulosa (Ipomoea carnea ssp fistulosa) (Tokarnia et al. 1960, 2000, Armién 2000).

Animais que consomem continuamente essas plantas desenvolvem sinais clínicos progressivos, que refletem fundamentalmente as alterações degenerativas no sistema nervoso central. Estes sinais clínicos incluem incoordenação, dismetria, hiperestesia, tremores musculares, quedas, depressão e emagrecimento (Molyneux \& James 1982, Balogh et al. 1999, Tokarnia et al. 2000). Alterações reprodutivas caracterizadas por diminuição na fertilidade e abortos têm também sido relatados (James et al. 1981).

Vacuolização citoplasmática de neurônios e células gliais são os achados histológicos mais significativos, mas não caracterizam o diagnóstico. Uma ferramenta importante para identificação de oligossacarídeos específicos armazenados no interior da célula é a análise histoquímica com lectinas. As lectinas são proteínas de origem não imune que se ligam de maneira reversível e com alta especificidade sacarídeos (Lis \& Sharon 1998). Em casos de doença de armazenamento, a análise por histoquímica de lectinas auxilia no diagnóstico ao identificar os açúcares específicos acumulados no citoplasma celular (Alroy et al. 1984, Alroy et al. 1986, Jolly \& Walkley, 1997).

\section{MATERIAL E METODOS}

\section{Classificação botânica}

Amostras da planta, coletadas nas propriedades com casos de intoxicação natural e utilizadas para a reprodução experimental, foram identificadas como Sida carpinifolia L.f. pela Dr ${ }^{\text {a }}$ Olinda Leites Bueno da Fundação Zoobotânica do Rio Grande do Sul, Porto Alegre, RS.

\section{Casos clínicos e necropsias}

Os históricos clínicos da doença nos caprinos foram obtidos junto aos proprietários dos estabelecimentos. São descritos três surtos em diferentes municípios do Estado do Rio Grande do Sul (Quadro 1).

Surto 1. Ocorrido no município de Lajeado, RS. Propriedade de 5 hectares, com 28 caprinos da raça Anglo-Nubiano e Saanen,

Quadro 1. Características físicas e dados clínicos dos caprinos em casos naturais e dos experimentalmente intoxicados por Sida carpinifolia

\begin{tabular}{cccccc}
\hline Caprino & Surto & Idade (meses) & Sexo & Raça & Sinais clínicos \\
\hline 1 & 1 & 36 & Fêmea & Saanen & $+++{ }^{\mathrm{b}}$ \\
2 & 1 & 24 & Fêmea & Anglo-Nubiana & ++ \\
3 & 1 & 24 & Fêmea & Anglo-Nubiana & ++ \\
4 & 1 & 36 & Fêmea & Mestiça & +++ \\
5 & 2 & 24 & Fêmea & Saanen & ++ \\
6 & 2 & 38 & Fêmea & Saanen & ++ \\
7 & 2 & 36 & Fêmea & Saanen & + \\
8 & 2 & 30 & Fêmea & Saanen & + \\
9 & 3 & 4 & Macho & Mestiça & ++++ \\
10 & 3 & 28 & Fêmea & Mestiça & +++ \\
11 & 3 & 18 & Fêmea & Mestiça & ++++ \\
12 & Exp. & 48 & Fêmea & Saanen & + \\
13 & Exp. & 6 & Macho & Anglo-Nubiana & - \\
14 & Exp. & 36 & Macho & Mestiço & ++++
\end{tabular}

${ }^{\mathrm{a}}$ Experimental.

$\mathrm{b}_{+}+++$Acentuados, +++ moderados, ++ leves, + discretos, - ausentes. 
utilizados para produção de leite. Estavam clinicamente afetados seis animais. Foram eutanasiados e necropsiados quatro animais deste surto, sendo que um deles foi retirado da propriedade, colocado em uma baia de alvenaria, alimentado com feno de alfafa e ração comercial e acompanhado por um período de 24 meses.

Surto 2. Ocorreu na localidade Lami, município de Porto Alegre. Em um rebanho leiteiro com 19 caprinos da raça Saanen, que pastoreavam em um piquete infestado por Sida carpinifolia e Sida rhombifolia, oito estavam clinicamente doentes. Os caprinos foram retirados do piquete e, um mês após, quatro dos animais afetados foram encaminhados para o setor de Patologia da UFRGS, eutanasiados e necropsiados.

Surto 3. Ocorreu em uma propriedade de 10 hectares localizada no município de Glorinha. Esta propriedade foi adquirida, no mês de agosto de 1999, sendo que 14 caprinos mestiços foram introduzidos na propriedade. Em dezembro de 1999, dois caprinos foram vistos doentes e, até março de 2001, outros dez apresentavam sinais clínicos. Os dois primeiros caprinos afetados, um macho e uma fêmea, foram separados do rebanho, colocados em um piquete livre de S. carpinifolia e mantidos na propriedade. Um animal eutanasiado e outros dois, que morreram afogados em um córrego da propriedade, foram necropsiados.

\section{Reprodução Experimental}

Para o estudo experimental, três caprinos oriundos de propriedades livres de Sida carpinifolia foram mantidos em baias individuais. Os Caprinos 12 e 13 receberam S. carpinifolia verde e triturada através de sonda esofágica na dose diária de $10 \mathrm{~g} / \mathrm{kg}$ e $20 \mathrm{~g} / \mathrm{kg}$ durante 60 e 90 dias, respectivamente, e o Caprino 14 recebeu a planta seca à sombra, triturada em moinho-martelo e fornecida à vontade, no cocho, para consumo espontâneo. 0 animal comeu em média $420 \mathrm{~g} /$ $\mathrm{kg} / \mathrm{dia}$, com variações de 100 a $900 \mathrm{~g} / \mathrm{dia}$, durante 105 dias; diariamente eram fornecidas cerca de $500 \mathrm{~g}$ de alfafa. Adicionalmente, todos os animais recebiam feno de alfafa, ração comercial, capim napier (Pennisetum purpureum) e água à vontade. Exames clínicos diários consistiam de avaliação postural, movimentação, temperatura retal, motilidade ruminal, freqüência cardíaca e respiratória, teste HR (Head rising) conforme Pienaar et al. (1976). Este teste consiste em flexionar-se a cabeça do animal em pé, para cima e caudalmente, aproximando-se a região frontal craniana da linha dorsal torácica e, após alguns segundos, soltá-la rapidamente. Animais com alterações neurológicas, especialmente cerebelares e vestibulares, demonstram incoordenação motora e ataques epileptiformes, quando submetidos a tal procedimento. Um quarto caprino recebeu no cocho, Sida rhombifolia fresca, à vontade, coletada no município de Porto Alegre, durante 40 dias.

\section{Estudo histológico}

Durante a necropsia, fragmentos de vários órgãos, incluindo o sistema nervoso central, foram fixados em solução formalina tamponada $10 \%$ e rotineiramente processadas para estudo histológico. Seções foram coradas com hematoxilina e eosina (HE). Para este estudo, foram analisadas seç̧ões coronais do córtex cerebral sobre o diencéfalo, tálamo, mesencéfalo, cerebelo com pedúnculos cerebelares e bulbo. Cortes transversais das intumescências cervical e lombar da medula espinhal foram também avaliados. Secções do cerebelo foram submetidas às colorações de ácido periódico de Schiff e impregnação pela prata.

\section{Histoquímica de lectinas}

Secções do cerebelo foram submetidos a uma bateria com 9 lectinas de diferentes especificidades (Quadro 2). As secções, depois
Quadro 2. Tipos de lectinas usadas no estudo histoquímico de caprinos intoxicados com Sida carpinifolia

\begin{tabular}{lcc}
\hline \multicolumn{1}{c}{ Lectina } & Acrossemia & Especificidade Carbohidrato $^{\mathrm{a}}$ \\
\hline Concanavalia ensiformis & Con A & $\alpha$-D-Man; $\alpha$-D-Glc \\
Glycine max & SBA & $\alpha$-D-GalNAc; $\beta$-D-GalNAc; $\alpha$ e $\beta$-Gal \\
Dolichos biflorus & DBA & $\alpha$-D-GalNAc \\
Ulex europaeus-I & UEA-1 & $\alpha$-L-Fuc \\
Triticum vulgaris & WGA & $\beta$-D-GlcNac, NeuNac \\
Succinyl-WGA & sWGA & $(\beta-(1-4)-D-G l c N a c)^{2}$ \\
Arachis hypogaea & PNA & $\beta$-D-Gal(1-3) GalNAc \\
Ricinus communis -I & RCA-I & $\beta$-D-Gal $>\alpha$-D-Gal \\
Bandeirea simplicifolia & BS-I & $\alpha$-D-Gal
\end{tabular}

a Goldstein \& Hayes (1978). Fuc $=$ Fucose; Gal = Galactose; GalNac $=$ N-acetylgalactosamine; $\mathrm{Glc}=$ Glicose; $\mathrm{GlcNac}=\mathrm{N}$-acetyl-glicosamina; Man $=$ Manose; NeuNac $=$ ácido $\mathrm{N}$-acetil-neuraminico.

Quadro 3. Intensidade da ligação de lectinas nas células cerebelares de caprinos afetados em relação ás células cerebelares dos caprinos normais

\begin{tabular}{lcccccccccc}
\hline Células de & \multicolumn{1}{c}{ Lectinas } \\
\cline { 2 - 4 } & sWGA & WGA & UEA-1 & PNA & SBA & RCA-1 & DBA & Con A & BS-1 \\
\hline Doente & $3^{\text {a }}$ & 3 & $0-2$ & 0 & $0-2$ & $0-1$ & $0-1$ & 3 & 0 \\
Normal & 0 & 1 & 0 & 0 & 0 & 0 & 0 & 1 & 0
\end{tabular}

anúmeros indicam a intensidade subjetiva de reação: $0=$ sem reação, $3=$ forte marcação,

de desparafinadas e hidratadas, foram incubadas em peróxido de hidrogênio $0,3 \%$ e metanólico durante 30 minutos em temperatura ambiente. Lavadas várias vezes em tampão fosfato $0,01 \mathrm{M}(\mathrm{PBS}), \mathrm{pH}$ 7.2 e tratadas com soro-albumina bovina 0,1 em PBS, por 15 minutos. Posteriormente, foram incubadas com lectinas biotiniladas por 1 hora, seguido por incubação com complexo peroxidase-avidinabiotina $(\mathrm{ABC})$ por 45 minutos. A peroxidase foi marcada por incubação de 4 a 10 minutos com solução tampão Tris- $\mathrm{HCl} 0,05 \mathrm{M} \mathrm{pH} \mathrm{7,6}$ contendo diaminobenzidina (DAB) $0,02 \%$ e $\mathrm{H}_{2} \mathrm{O}_{2} 0,05 \%$. Todas as secções foram contracoradas com hematoxilina de Mayer.

Cada lectina foi utilizada em diluição de $30 \mathrm{mg} / \mathrm{ml} \mathrm{em} \mathrm{PBS,} \mathrm{exceto}$ a PNA, a qual foi aplicada a uma concentração de $10 \mathrm{mg} / \mathrm{ml}$. Como controle para histoquímica, a lectina foi omitida ou bloqueada em incubação com seus açúcares bloqueadores (0,1-0,2 em PBS) por uma hora em temperatura ambiente (Goldstein \& Hayes 1978).

\section{RESULTADOS}

Os principais sinais clínicos dos caprinos naturalmente afetados foram similares nos três surtos, e consistiram de ataxia com hipermetria e dismetria, tremores de cabeça e pescoço, teste HR positivo, nistagmo, quedas freqüentes e posturas atípicas (Fig. 2): escorando-se em objetos com membros cruzados ou sentando-se com os membros posteriores voltados para trás. Os animais movimentavam-se mais lentamente. Emagrecimento foi um achado comum. Os caprinos mantinham $o$ apetite, mas tinham dificuldades para ingerir alimentos e água. Os sinais clínicos exacerbavam-se durante a movimentação. As mortes ocorreram por causas incidentais. No Surto 1, vários animais afetados morreram após ataque de abelhas (Apis mellifera). No Surto 3, ocorreram três mortes 

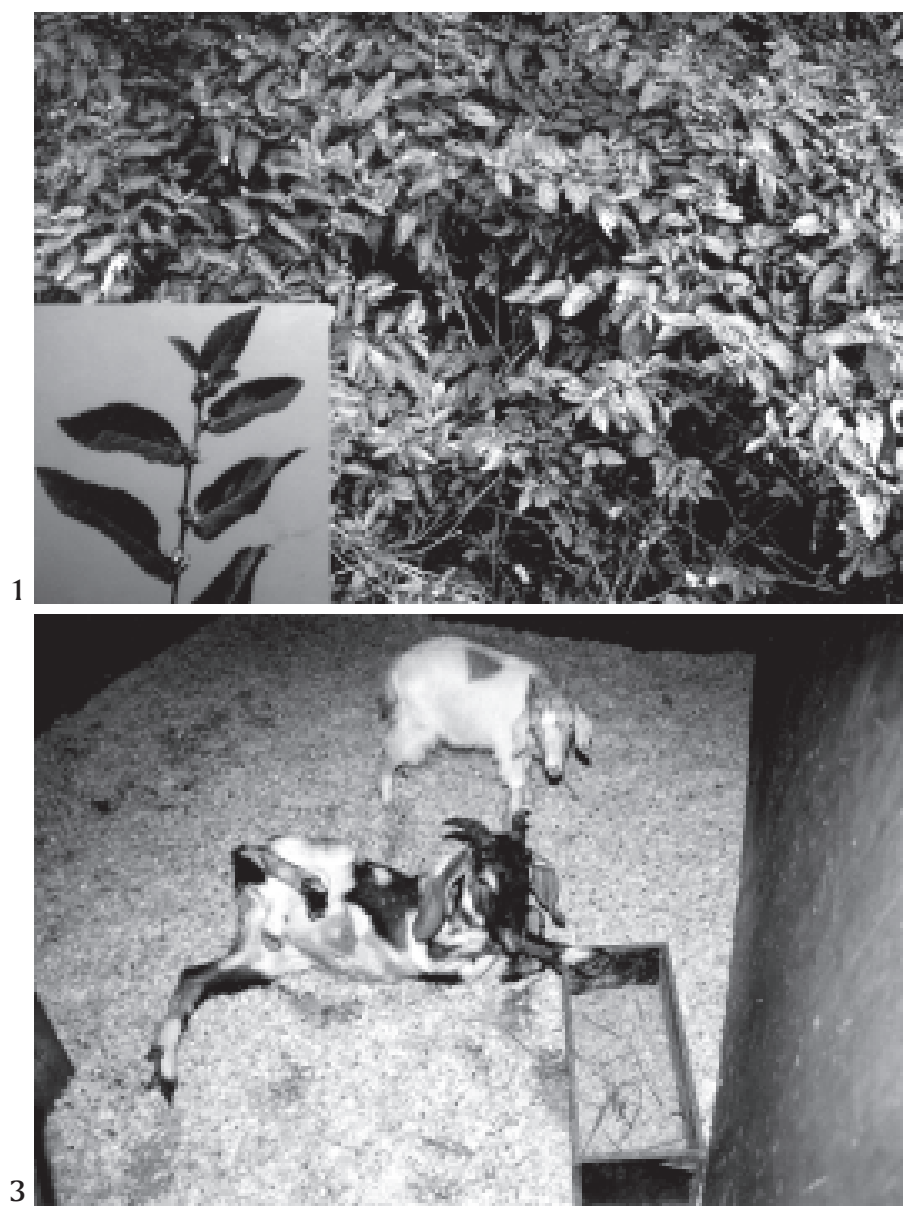

por afogamento. No Surto 2, em que os animais foram afastados do piquete com Sida carpinifolia, a incoordenação motora era evidente, mas com menor intensidade em relação aos outros surtos. Inclusive havia diminuição ou ausência de resposta ao teste $\mathrm{HR}$, os tremores musculares eram discretos ou ausentes e os animais afetados acompanhavam os aparentemente normais. O Caprino 4 (Surto 1), que foi acompanhado durante 24 meses, inicialmente estabilizou seu quadro clinico, de forma similar ao ocorrido com os caprinos no Surto 2, parindo normalmente três vezes consecutivas. Após o terceiro parto, a incoordenação motora acentuou-se, sendo que ela não conseguia amamentar pois permanecia em decúbito lateral, embora tentasse se levantar. Como tal quadro não cedeu, este animal foi eutanasiado.

O Caprino 14 recebeu a planta seca ad libidum, consumindo em média $420 \mathrm{~g} / \mathrm{kg}$, e apresentou alterações clínicas similares àquelas demonstradas pelos casos naturais. Os primeiros sinais foram observados 35 dias após o início da administração e caracterizaram-se por letargia e incoordenação motoras moderadas. Ao teste HR, a queda era em decúbito lateral ou abdominal, nesta posicionando-se com os membros posteriores abertos. Os sinais foram progressivos e, aos 105 dias do período experimental, o animal apresentava tremores de cabeça e pescoço, nistagmo e normalmente caminhava se estivesse escorado, caindo com freqüência (Fig. 3). Dos dois ani-

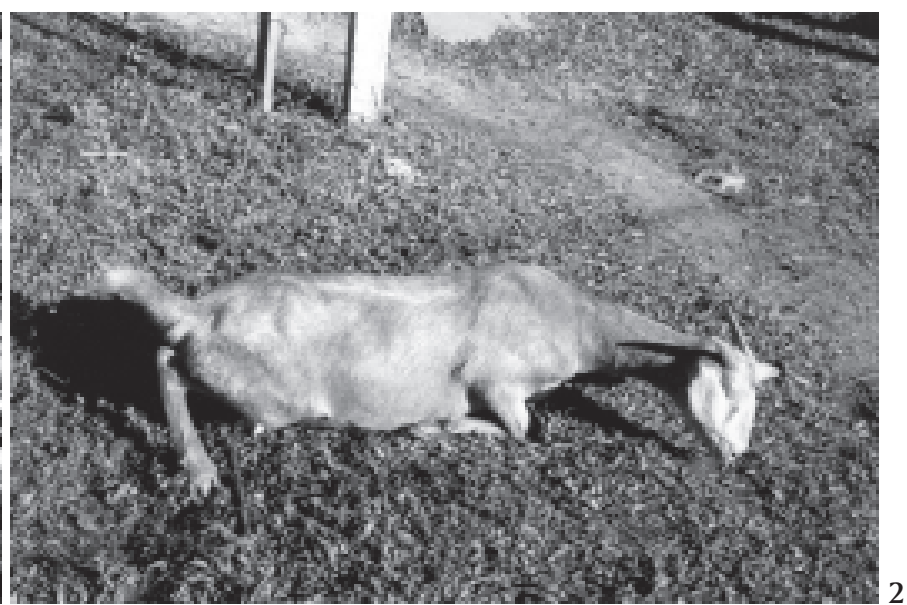

Fig. 1. Sida carpinifolia L.f. (fam. Malvaceae). Detalhe mostrando folhas alternadas e inflorescência axilar.

Fig. 2. Caprino 4 com posição atípica e dificuldade para se levantar. Intoxicação natural por Sida carpinifolia.

Fig. 3. Caprino 14. Decúbito lateral. Este animal fazia esforços para se levantar, às vezes por alguns minutos, sem êxito. Intoxicação experimental por Sida carpinifolia.

mais que receberam $S$. carpinifolia verde e triturada através de sonda esofágica, o Caprino $12(10 \mathrm{~g} / \mathrm{kg})$ apresentou leves sinais clínicos ao final do experimento, incluindo leves tremores de cabeça, discreta instabilidade ao caminhar e quedas ao teste HR. O Caprino $13(20 \mathrm{~g} / \mathrm{kg})$ não apresentou alterações clínicas durante os noventa dias do experimento.

Um achado freqüente durante as necropsias foi o aumento de volume de linfonodos, principalmente dos mesentéricos. Nos demais órgãos, não foram notadas alterações significativas.

Microscopicamente, nos Caprinos 1, 2, 3, 9, 10, 11, 12, 13,14 , foram mais significativos os achados no sistema nervoso central e caracterizaram-se por distensão e vacuolização citoplasmática múltipla e acentuada, afetando principalmente as células de Purkinje do cerebelo (Fig. 4) e os neurônios do córtex cerebral, do tálamo, do mesencéfalo e da medula espinhal. Não houve marcação dos vacúolos intracitoplasmáticos pela coloração com PAS. Esferóides axonais foram freqüentemente encontrados na camada granular do cerebelo e, com menor intensidade, em outras áreas do encéfalo e medula espinhal. Em alguns neurônios, principalmente os de Purkinje, além da marcada vacuolização, o citoplasma remanescente apresentava-se com forte eosinofilia e ocupava pequena parte, normalmente na periferia da célula. Nos Caprinos 9, 11 e 14, cujos sinais clínicos eram acentu- 


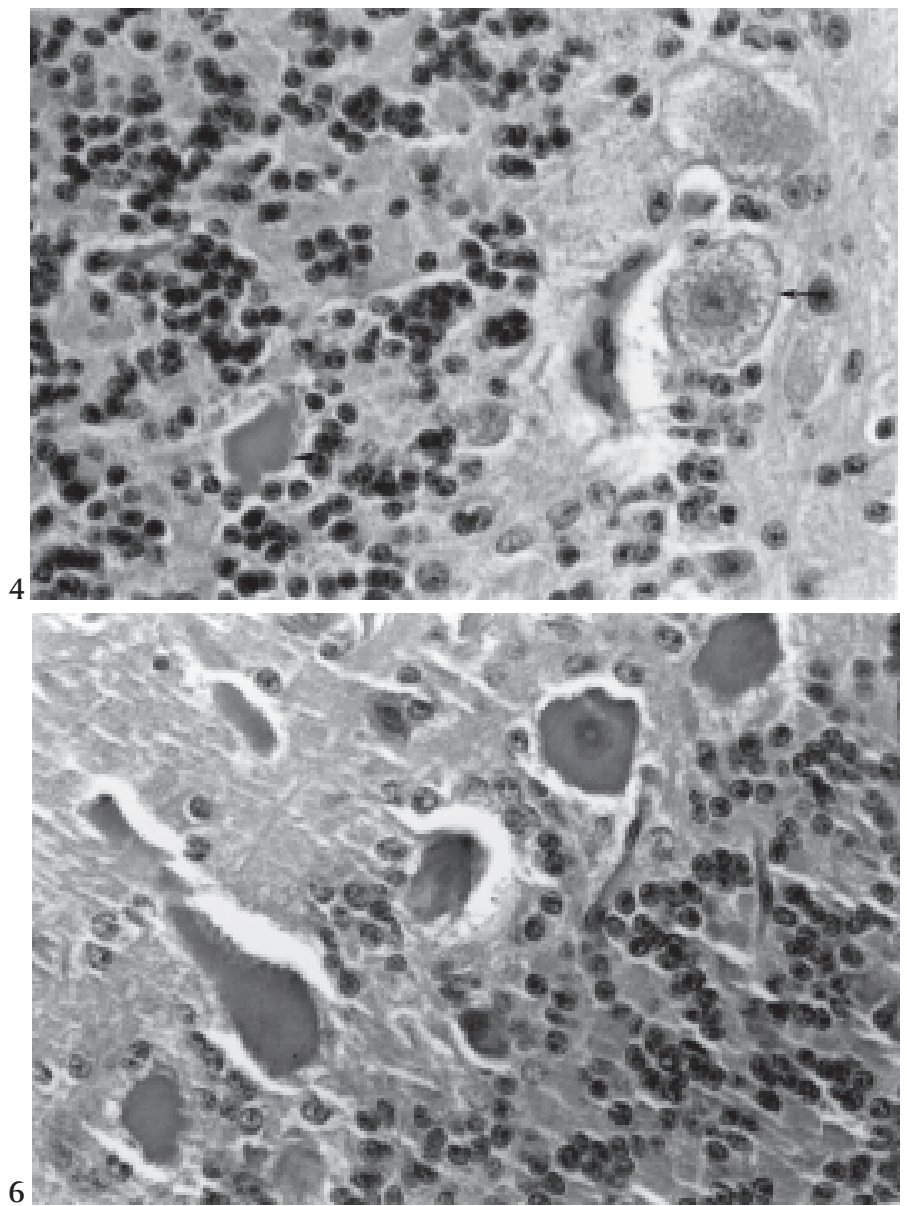

ados, observaram-se vacuolização neuronal marcada e difusa, vacuolização de células da glia, especialmente oligodendrócitos, e aumento da quantidade de esferóides axonais. Nos Caprinos 2, 3, 5, 6, 7, 8 e 12, cujos sinais clínicos foram discretos ou leves, as lesões eram confinadas às células de Purkinje do cerebelo e neurônios medulares. Vacuolização citoplasmática foi também observada no epitélio dos ácinos pancreático e dos túbulos renais, na folicular da tireóide, nos hepatócitos e macrófagos de órgãos linfóides. Nos animais do Surto 2, as lesões estavam limitadas ao sistema nervoso central, sendo notada menor intensidade ou ausência de distensão e de vacuolização citoplasmática neuronal. Entretanto, encontravam-se, com freqüência, neurônios eosinofilicos com citoplasmas diminuídos e enrugados (Fig. 5) e com núcleos condensados e hipercromáticos. No SNC do Caprino 4 (Surto 1), não foi encontrada vacuolização neuronal, porém observou-se desaparecimento neuronal, principalmente de células de Purkinje, além de astrogliose local e uma menor densidade de neurônios na camada granular do cerebelo. O caprino que consumiu em média $40 \mathrm{~g} / \mathrm{kg} / \mathrm{dia}$ de Sida rhombifolia durante 40 dias, não desenvolveu alterações clínicas nem patológicas.

Constatou-se pela análise das secções de cerebelo dos Caprinos 1, 5, 11 e 12 que o padrão da reação de lectinas foi similar entre os animais intoxicados natural ou experimental-

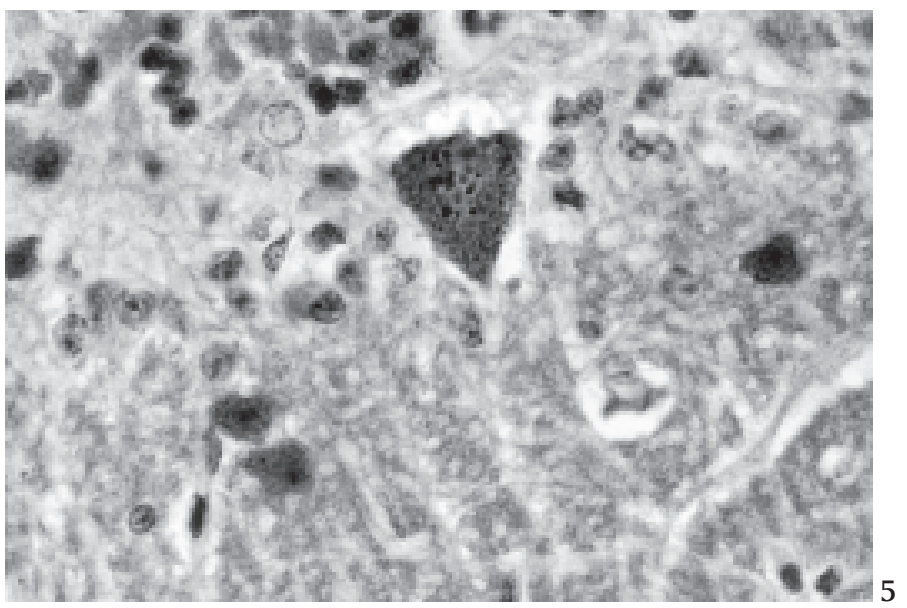

Fig. 4. Caprino 11. Secção cerebelar mostrando células de Purkinje (seta) com citoplasma distendido e intensamente vacuolizado. Esferóide axonal (cabeça de seta) na camada granular. Intoxicação natural por Sida carpinifolia em caprinos. HE, obj. 40 .

Fig. 5. Cerebelo do Caprino 7, naturalmente intoxicado por Sida carpinifolia. As células de Purkinje estão com o citoplasma eosinofílico e enrugado. HE, obj. 40.

Fig. 6. Cerebelo do Caprino 1. As células de Purkinje e neurônios das camadas granular e molecular mostram forte marcação citoplasmática após serem incubados com Triticum vulgaris succinilado e contracorados com hematoxilina de Mayer. Obj. 40 .

mente. Tais seç̧ões, quando comparadas àquelas de animais controles que não ingeriram Sida carpinifolia, evidenciaram que os citoplasmas das células de Purkinje e demais células das camadas molecular e granular do cerebelo coraram-se fortemente com Concanavalia ensiformis (Con A), Triticum vulgaris (WGA), e succinil-WGA (sWGA) (Fig. 6). Fraca marcação foi observada ao Ulex europaeus I (UEA-1), Glycine max (SBA), Dolichos biflorus (DBA) e Ricinus cummunis I (RCA-1). Seç̧ões incubadas com Bandeirea simplicifolia (BS-1) e com Arachis hyogaea (PNA) não foram marcadas. (Quadro 3)

\section{DISCUSSÃO}

A ingestão de Sida carpinifolia por caprinos induz à doença de armazenamento lisossomal caracterizada como $\alpha$-manosidose através da histoquímica com lectinas (Driemeier et al. 2000). S. carpinifolia é atualmente a única espécie da família Malvaceae associada com doença de armazenamento lisossomal. Experimentalmente, Sida rhombifolia não causou quaisquer sinais clínicos nem lesões histológicas. Nos três surtos descritos neste estudo, S. carpinifolia invadia grandes áreas das propriedades e, por vezes, era a vegetação predominante nos potreiros onde os animais eram mantidos. Observou-se que os animais que desenvolveram sinais clínicos espontâneos adquiriram avidez para pastorear S. carpinifolia, mesmo tendo outros alimentos à disposição. 
Os achados clínicos e patológicos da intoxicação por $S$. carpinifolia em caprinos observados neste estudo foram semelhantes aos descritos em casos de consumo de plantas do gênero Swainsona, Oxytropis, Astragalus e Ipomoea (Tokarnia et al. 1960, Kingsbury 1964, James \& Nielsen 1990, Colegate et al. 1979, Balogh et al. 1999, Armién 2000, Tokarnia et al. 2000).

$O$ alcalóide indolizidina 1,2,8-triol (swainsonina), isolado de amostras de Sida carpinifolia deste estudo, é descrito como inibidor da atividade das enzimas $\alpha$-manosidase e $\alpha$ manosidase II do aparelho de Golgi (Dorling et al. 1980). O decréscimo da atividade da $\alpha$-manosidase resulta no acúmulo lisossomal de oligossacarídeos incompletamente processados (Tulsiani et al. 1982, Stegelmeier et al. 1995). A $\alpha$-manosidase II do aparelho de Golgi está envolvida no processamento de oligossacarídeos durante a glicosilação de proteínas, de forma que sua deficiência causa o acúmulo de oligossacarídeos contendo manose nos lisossomos. Os resíduos armazenados não têm sido considerados diretamente tóxicos para a célula. Os sinais clínicos e lesões descritos nesta doença estariam associados aos efeitos mecânicos do armazenamento de oligossacarídeos e ao impedimento do transporte citoplasmático (Agamanolis 1995).

Infertilidade, abortos e nascimento de animais fracos foram constatados neste estudo e têm sido freqüentemente descritos nas intoxicações por plantas que contêm swainsonina (Hartley \& James 1975, Panter et al. 1987). Entretanto, depois de alguns meses sem ingerir $S$. carpinifolia, um casal de caprinos do Surto 3, além do Caprino 4, foram capazes de gerar produtos normais. Estes achados sugerem que, embora alterações reprodutivas possam ser comuns durante o consumo de $S$. carpinifolia, o ciclo reprodutivo pode voltar ao normal após a restrição do consumo da planta.

Após cessar o consumo de plantas com swainsonina, o nível sérico da enzima $\alpha$-manosidase e o nível urinário de excreção de oligossacarídeos retornam ao normal em aproximadamente uma semana. Os animais que apresentam sinais clínicos leves e param de consumir plantas com este princípio tóxico podem recuperar-se espontaneamente (Daniel et al. 1984, Stegelmeier et al. 1995). No presente estudo, não foi observada reversão do quadro após o consumo de $S$. carpinifolia. Em caprinos cujos tecidos foram analisados histologicamente durante e após restrição de consumo da planta, observaram-se neurônios vermelhos e encarquilhados, formação de esferóides axonais e gliose no cerebelo, núcleos basais e medula espinhal. Menor intensidade ou ausência de vacuolização neuronal ocorreu naqueles caprinos que foram retirados dos potreiros com S. carpinifolia. Em observações feitas 24 meses após interrompido o consumo de $S$. carpinifolia, constatou-se desaparecimento neuronal, principalmente de células de Purkinje, as quais acredita-se serem mais vulneráveis à deficiência de $\alpha$-manosidase (Tirkey et al. 1987). Lesões similares às encontradas neste trabalho foram associadas ao consumo de Ipomoea carnea (Balogh et al. 1999).

\section{REFERÊNCIAS}

Agamanolis D.P. 1995. The pathology of lysosomal storage diseases. Pathol. Annu. 30: 247-285.
Alroy J., Orgad U., Ucci A.A. \& Pereira M.E.A. 1984. Identification of glycoprotein storage diseases by lectins: a new diagnostic method. J. Histochem. Cytochem. 32: 1280-1284.

Alroy J.U., Ucci A.A., Goyal V.G. \& Woods W. 1986. Lectin histochemistry of glycolipids storage diseases on frozen and paraffin-embedded tissue sections. J. Histochem. Cytochem. 34:501-505.

Armién A.G. 2000. Vergleichende klinische und morphologische Untersuchungen zur spontanen und experimentellen Vergiftung durch Ipomoea fistulosa (Convolvulaceae) bei Ziegen. Dissertation, Justus-LiebigUniversität Giessen, Alemanha. 212p.

Balogh K.K.I.M., Dimande A.P., Lugt J.J., Molyneux R.J., Naudé T.W. \& Welman W.G. 1999. A lisosomal storage disease induced by Ipomoea carnea in goats in Mozambique. J. Vet. Diagn. Invest. 11:266-273.

Colegate S.M., Dorling P.R. \& Huxtable C.R. 1979. A spectroscopic investigation of swainsonine: an alpha-mannosidase inhibitor isolated from Swainsona canescens a plant poisonous to livestock.. Aust. J. Chem. 32:2257-2264.

Colodel E.M., Gardner D.R., Zlotwski P. \& Driemeier D. 2002. Identification of swainsonine as a glycoside inhibitor responsible for Sida carpinifolia poisoning. Vet. Hum. Toxicol. (In press)

Daniel P.F., Warren C.D. \& James L.F. 1984. Swainsonine-induced oligosaccharide excretion in sheep. Time-dependent changes in the oligosaccharide profile. Biochem. J. 221(3):601-607.

Dorling P.R., Huxtable C.R. \& Colegate S.M. 1980. Inhibition of lysosomal alpha-mannosidase by swainsonine, an indolizidine alkaloid isolated from Swainsona canescens. Biochem J. 191(2):649-651.

Driemeier D., Colodel E.M., Gimeno E.J. \& Barros S.S. 2000 Lysosomal storage disease caused by Sida carpinifolia poisoning in goats. Vet. Pathol. 37: 153159.

Goldstein I.J. \& Hayes C.E. 1978. The lectins: carbohydrate binding proteins of plants and animals. Adv. Carbohydr. Chem. Biochem. 35: 127-340.

Hartley W.J. \& James L.F. 1975. Fetal and maternal lesions in pregnant ewes ingesting locoweed (Astragalus lentiginosus). Am. J. Vet. Res. 36(6):825-826.

James L.F., Hartley W.J. \& van-Kampen K.R. 1981. Syndromes of Astragalus poisoning in livestock. J. Am. Vet. Med. Assoc. 178:146-150.

James L.F. \& Nielsen D. 1990. Locoweeds assessment of the problem on western U.S. rangelands. In: James L.F., Ralphs M.H. \& Nielsen D. (ed.) The Ecology and Economic Impact of Poisonous Plants on Livestock Production. Westview Press, Boulder. 428p.

Jolly R.D. \& Walkley S.U. 1997. Lysosomal storage diseases of animals: an essay in comparative pathology. Vet. Pathol. 34: 527-548.

Kingsbury J.M. 1964. Poisonous Plants of the United States and Canada. Prentice-Hall, Englewood Cliffs, New Jersey, p. 306-313.

Lis H. \& Sharon N. 1998. Lectins: Carbohydrate-Specific Proteins that mediate Cellular Recognition. Chem Rev. 98: 637-674.

Lorenzi H. 2000. Plantas Daninhas do Brasil: Terrestres, Aquáticas, Parasitas e Tóxicas. Família Malvaceae. $3^{\underline{a}}$ ed. Plantarum, São Paulo, p. 461-482.

Loretti A.P., Colodel E.M., Gimeno E.J. \& Driemeier D. 2002. Lysosomal storage disease in Sida carpinifolia toxicosis: an induced mannosidosis in horses. Equine Vet. J. (In press)

Molyneux R.J. \& James L.F. 1982. Loco intoxication: Indolizidine alkaloids of spotted locoweed (Astragalus lentiginosus). Science 216:190-191.

Panter K.E., Bunch T.D., James L.F.\& Sisson D.V. 1987. Ultrasonographic imaging to monitor fetal and placental developments in ewes fed locoweed (Astragalus lentiginosus). Am. J. Vet. Res. 48(4):686-690.

Pienaar J.G., Kellerman T.S., Basson P.A., JenKins W.L. \& Vahrmeyer J. 1976. Maldronksiekte in cattle: a neuropathy caused by Solanum kwebense N.E.Br. Onderstepoort J. Vet. Res. 43:67-74.

Stegelmeier B.A., Molyneux R.J., Elbein A.D. \& James L.F. 1995. The lesions of locoweed (Astragalus mollissimus), swainsonine, and castanospermine in rats. Vet. Pathol. 32: 289-298.

Tirkey K., Yadava K.P. \& Mandal T.K. 1987. Effect of aqueous extract of Ipomoea 
carnea on the haematological and biochemical parameters in goats. Indian J. Anim. Sci. 57:1019-1023.

Tokarnia C.H., Döbereiner J. \& Canella C.F.C. 1960. Estudo experimental sobre a toxidez do "canudo" (Ipomoea fistulosa Mart.) em ruminantes. Arq. Inst. Biol. Animal, Rio de J., 3:59-71.
Tokarnia C.H., Döbereiner J. \& Peixoto P.V. 2000. Plantas Tóxicas do Brasil. Editora Helianthus, Rio de Janeiro.

Tulsiani D.R.P., Harris T.M. \& Touster O. 1982. Swainsonine inhibits the biosynthesis of complex glycoproteins by inhibition of golgi mannosidase II. J. Biolog. Chem. 257:7936-7939. 